\title{
Адаптация жанров традиционного фольклора к условиям современного мира (на примере народнобиблейских и мифологических нарративов белорусско-русского пограничья)
}

\author{
Елена Боганева \\ Центр исследований белорусской культуры, языка \\ и литературы Национальной академии наук Беларуси \\ elboganeva@gmail.com
}

\begin{abstract}
Аннотация: Термин «адаптация» в антропологии и культурологии понимается как процесс взаимного приспособления между культурой и внешней средой, направленный на выживание и стабильность социальной системы. Культура не может существовать вне традиции, наиболее тесно связана с традицией устная этническая культура, которая является той «центральной зоной культуры» (Shils, Eisenstadt), что остается неизменной при любой смене инвариантов культурной традиции. До тех пор, пока эта «центральная зона» не разрушена, этнос сохраняет свою идентичность. Таким образом этническая культура является той базовой, «центральной» структурой, что консолидирует общество и предохраняет его от распада. В сельской местности Беларуси до сегодняшнего дня сохранилась живая этническая культура, хотя она и подвергается разнообразным трансформациям, адаптируясь к современной жизни и одновременно адаптируя к новым условиям ее носителей. В белорусской деревне существует смешанный тип культуры - письменный и традиционный устный, при том именно устные традиции определяют мировоззре-
\end{abstract}


ние, восприятие жизни, религиозность старших поколений сельских жителей. В системе народной религиозности на белорусско-русском пограничье преобладает народное православие. С одной стороны, это чрезвычайно устойчивая система, с другой стороны, в современном мире, тяготеющем к глобализации и унификации форм культуры, многие устные компоненты, в том числе разновидности народной прозы непосредственно связанные с народной религиозностью, постепенно маргинализуются, выходят из активного употребления и исчезают. Тем не менее на белорусско-русском пограничье в современных условиях сохраняются (преимущественно среди старшего поколения) и многократно записывались народнобиблейские нарративы по узловым топикам Священного Писания, а также традиционные сюжеты и представления о мифологических персонажах. В среде сельской интеллигенции среднего возраста в связи с распространением знаний о традиционных персонажах народной мифологии через письменные источники такой жанр, как былички (мифологические нарративы), адаптируется к современной действительности путем аккумулирования в своем содержательном плане местных и привнесенных элементов верований и образования некоего эклектичного целого.

Ключевые слова: адаптация, «центральная зона культуры», этническая культура, устный и письменный типы культуры, народная религиозность, народная проза, народная Библия, мифологические нарративы

\section{Традиция и культура как адаптационно- адаптирующие механизмы. Центральная зона культуры}

Термин «адаптация» первоначально был разработан в естественных науках и рассматривался как процесс приспособления к изменяющимся внешним условиям. Широкое распространение это понятие получило в психологии и других гуманитарных науках, в которых адаптация определяется как процесс приспособления индивида к внешней социальной среде. Эдуард Маркарян рассматривает культуру как адаптационно-адаптирующий способ деятельности человеческого общества или «как способ деятельности людей, который обеспечивает приспособление человека к природной и социальной среде и одновременно ведет к очеловечиванию среды и самого человека» (Маркарян 1983: 
135). Иначе говоря, человек при помощи культуры приспосабливается к окружающему миру и, одновременно, приспосабливает окружающий мир к себе - как практически-инструментально, так и символически.

Культура не может существовать вне традиции, в этой связи Кирилл Чистов писал о синонимичности терминов «культура» и «традиция» в определенном теоретическом контексте. Термин «культура» обозначает сам феномен, а «традиция» - механизм его функционирования. Т.е. традиция - это сеть (система) связей настоящего с прошлым, причем при помощи этой сети совершаются определенный отбор, стереотипизация опыта и передача стереотипов, которые затем опять воспроизводятся (Чистов 1981: 106; 1986: 108). Традиция является также механизмом аккумуляции, передачи (трансмиссии) и актуализации (реализации) человеческого опыта, а значит культуры (Чистов 2005: 118).

Особенно связана с традицией устная этническая культура, одно из названий которой - традиционная культура. Именно устная этническая культура является, по определению Маргарет Мид, постфигуративной по преимуществу (Мид 1988: 322-342), культурой преемственности, когда «каждое изменение протекает настолько медленно и незаметно, что деды, держа в руках новорожденных внуков, не могут представить себе для них никакого иного будущего, отличного от их собственного прошлого. [...] Без письменных или других средств фриксации прошлого люди вынуждены были включать каждое изменение в свое сознание, хранить его в памяти и отработанных фрормах действий каждого поколения взрослых. Основные навыки и знания передавались ребенку так рано, так беспрекословно и так надежно [...], что у ребенка не могло быть и тени сомнения в понимании своей собственной личности, своей судьбы. [...] Даже экстремальные условия вынужденных миграций [...] только подчеркивали это чувство преемственности» (Мид 1988: 322 323).

Важной в понимании механизмов функционирования культуры является концепция «центральной зоны культуры», выдвинутая Шмуэлем Эйзенштадтом (в некоторых переводах и транскрипциях Самуэлем Айзенштадтом). При всех трансформациях и любой смене инвариантов культурной традиции, присущей тому или иному этносу, неизменной остается «центральная зона» его культуры. До тех пор, пока эта «центральная зона» не 
разрушена, этнос сохраняет свою идентичность. Эйзенштадт показывает, что является «ядром», средоточием традиции, где локализуется ее харизматическое и символическое содержание, обращаясь к той трактовке культуры, которую дает Эдвард Шилз. Эйзенштадт пишет: «На макросоциальном уровне артикуляция символических и харизматических изменений институционального сосредоточена в том, что Эдвардом Шилзом было названо центром общества или общественным центром» (Eisenstadt 1973: 138). Сам Шилз описывает этот «общественный центр» или «центральную зону культуры» следующим образом: «У общества есть центр. В структуре общества существует центральная зона. [...] Членство в обществе определяется более отношением к этой центральной зоне, чем местом жительства на данной территории и адаптацией к окружающей среде. Центральная зона не является пространственно локализованным явлением. Она почти всегда имеет более или менее определенное место на ограниченной территории, в которой живет общество, однако ее «центральность» не имеет ничего общего ни с геометрией, ни с географией. Центр или центральная зона - это явление из области ценностей и убеждений, которые управляют обществом. Именно центр упорядочивает символы, ценности и верования. Это центр, потому что он является конечным и нередуцируемым; и он ощущается центром также теми многими [членами общества], кто не может эксплицитно выразить его предельность. Центральная зона определяет природу священного. В этом смысле каждое общество имеет «официальную» религию, даже если представители и интерпретаторы этого общества более или менее правильно понимают его как светское, плюралистическое и толерантное. Принцип контрредрормации: Cujus regio, ejus religio (чья земля, того и вера), хотя и в ослабленном виде, сохраняет свою истинность. Кроме того, центр является феноменом области действий. Он представляет собой структуру активности, ролей и действующих лиц в рамках сети институций. Именно в этих ролях воплощаются те ценности и убеждения, которые являются для данного общества центральными. [...] Существование центральной системы ценностей обусловлено потребностью людей принадлежать к более высокой сфере, чем они сами, тому, что превосходит и преображает их конкретную индивидуальную жизнь» (Shils 1961: 117) (пер. Е. Б.). 
Здесь надо оговорить, что сам Шилз концепцию «центра культуры» не связывал с концепцией традиции. Идея применить концепцию «центральной зоны» к объяснению феномена традиции принадлежит Эйзенштадту. Он дает и собственную, отличную от той, которую давал Шилз, трактовку содержания центральной зоны культуры, составляющих ее компонентов (Eisenstadt 1973: 138; Эйзенштадm 1998: 470-479; Лурье 1997: 183). И эта интерпретация Эйзенштадта оказывается особенно актуальной для обществ, у которых подобно белорусскому существует в аутентичной форме традиционная этническая культуpa, т.к. именно она является той структурой, что консолидирует данное общество и предохраняет его от распада.

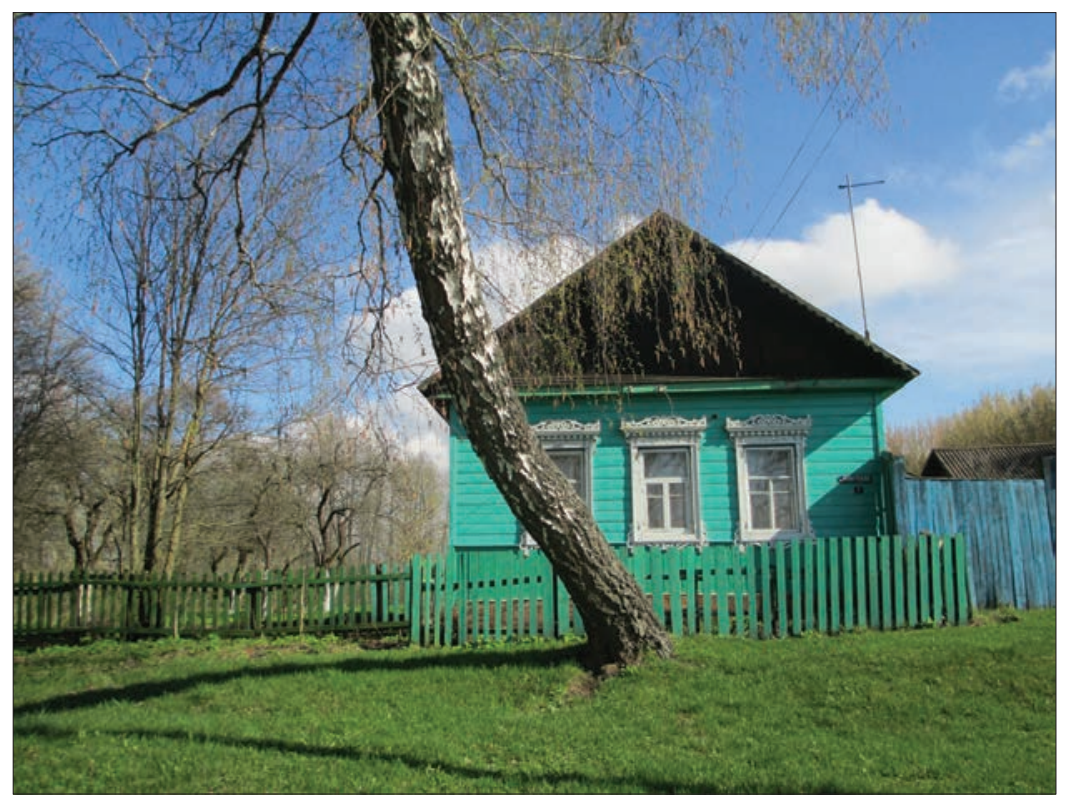

Фото 1. Деревня Неглюбка Ветковского района Гомельской области. Фото Е. Боганевой. 


\section{Факторы, оказывающие влияние на современное состояние традиционной культуры. Писыменный и устный типы культуры}

В сельской местности Беларуси до сегодняшнего дня сохранилась живая этническая культура, хотя она и подвергается разнообразным трансформациям. Она адаптируется к современной жизни и одновременно адаптирует к новым условиям ее носителей. В белорусской деревне существует смешанный тип культуры - письменный и традиционный устный, при том именно устные традиции определяют мировоззрение, восприятие жизни, религиозность старших поколений сельских жителей. Они существуют, подвергаясь взаимным влияниям, но фрункционируют скорее параллельно и самостоятельно, по своим законам.

Как известно, письменный и устный тип культуры принципиально различны главным образом в составе участников коммуникативной ситуации и возможности варьирования текста, когда вчерашний слушатель (реципиент) становится исполнителем - субъектом коммуникативного процесса (см. об этом Чистов 2005: 26-43). И, хотя письменный (технический) тип воспроизведения и трансляции культуры в современном мире доминирует, фольклорная устная культура на белорусско-русском пограничье не вытесняется до конца письменной. Об этом свидетельствует широкий круг носителей традиции, в том числе среди поколений среднего возраста - 40-x-60-х гг. рождения, активное устное бытование текстов народной прозы, их высокая «плотность» на единицу территории, образование выразительных локализаций сюжетно-персонажных единиц и комплексов (речь идет об этиологических легендах и быличках), когда в микроареале распространен определенный тип сюжетной версии, мотив или мифологический персонаж. Последнее создает условия для картографирования выделенных элементов и получения важных особенностей локальных культур региона даже на современном фольклорном материале, что указывает на достаточно высокую степень его сохранности (см. об этом Боганева 2006: 196-204, 2015: 171-189; Авілін 


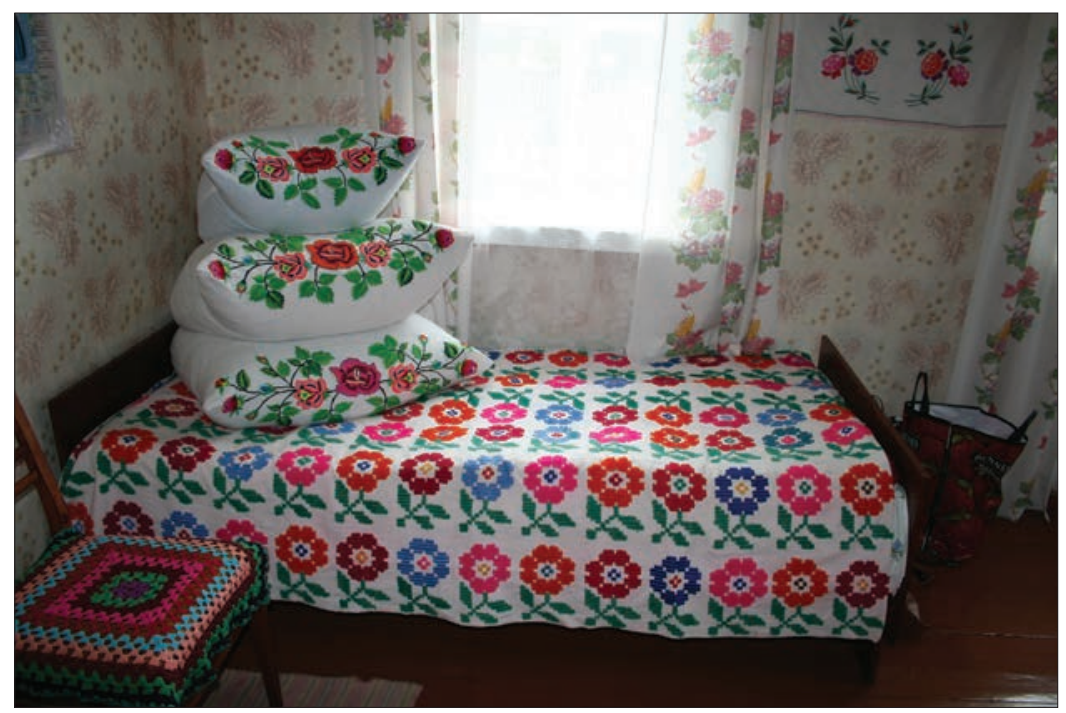

Фото 2. Интерьер (ручное ткачество и вышивка) в деревне Ананчицы Солигорского района Минской области. Фото Е. Боганевой.

\& Антропаў \& Боганева 2016: 232-273; Боганева \& Авілін 2017: 112-149; Авілін \& Аліфрерчык \& Боганева 2018 (в печати); Антропов \& Авилин \& Боганева 2018 (в печати)).

Письменная культура оказывает на устную значительное влияние, при том, что естественная трансмиссия народной культуры - от народной прозы до верований - продолжает осуществляться устным путем. В чем заключается это влияние? Прежде всего в том, что жители старшего поколения деревень и местечек, те, кого мы называем носителями традиции, за редким исключением являются грамотными людьми, уровень образования которых от 1-2-х классов начальной школы до среднего специального образования (в редких случаях встречается высшее образование - преимущественно у сельских учителей). Т.е. носители традиции одновременно принадлежат к культуре как устной, так и письменной и в любом случае пользуются техническими средствами получения информации - радио, телевидением и т. п. Носители культуры устного типа также являются «потребителями» современной информационной и культурной 
продукции письменного типа. Часто, усвоив какой-то сюжет из письменного источника, информант начинает рассказывать его уже устно, и хотя этот сюжет не входит в традицию, но по типу его воспроизведения, трансляции, интерпретации, он становится вполне традиционным.

Например, в Городокском районе в конце 1990-х гг. жила талантливая рассказчица Марфа Ивановна Морозова (1917 г. р., 4 кл.). Сказки, которые она рассказывала, были ею когда-то прочитаны (это были сказки Пушкина), но потом она рассказывала их устно и взрослым, и детям, переходя попеременно со стиха на прозу и комментируя отдельные места (см. тексты этих сказок (ТМКБ 2004: 744-751). В беседе о своем усвоении сказок и их последующем воспроизведении она рассказала следующее: «[А якія казкі раней у вас расказвалі? Такія як у кніжках або не такія?] A нікакіе. Абы-што, быьала, сыпециа. Зберуица лужукі. Старые ж, знаеце, какіе былі скалейкі - дліннья! Дь мужык прійдзець, жопу перявесіиь черяз скалейку, ку-у-ріць, ды плюець, ды пад ногі табаку сыплециа. Што яны тал будуць гаваріць? Хто пра вайну станець расказваць... Сказак дужа я не чула ні ад каго. Я толькі во сказкі з кніжак сала. I каторая заінцересуець мяня, раза два прачытаю - $і$ яна ўжо мая. [...] [А дзецям сваім Вы казкі расказвалі?] Маіл собственна дзеияли? [Любым.] А любылм я $і$ зараз усягда расказваю сказкі. [Любяць Вас слухаць?] Любяць $і$ слухаць, любяць ка лне $і$ хадзіць рябять у усі. У Паску ужо дык каждьй прійдзець, гасиіниу прінясещь, і я ужо варю яеи иэлую карзіну. Нада ж усіл даваць рябятал. Дзецкій празнік такей. [...] Люблю расказваиь, люблю чытаць. Вот ужо сказкі мне... А еслі ралан харошый какей - тожа люблю. Тадь магу і расказаць пра тот ралан» (зап. Е. Боганева и Т. Варфоломеева в 1998 г. от Марфы Морозовой, 1917 г. р., 4 кл., прав., д. Вышедки, Городокский р-н, Витебская обл.).

Устная фольклорная традиция постепенно утрачивает свои позиции и маргинализуется, однако этот процесс неоднороден для разных видов и жанров традиционной культуры. В некоторых случаях явление или жанр еще существуют в памяти носителей традиции и при востребованности (в том числе в ситуации фольклорных экспедиций, когда появляется собиратель) актуализируются. Но прерывается естественная трансмиссия, утрачиваются ситуации общения, когда тот или иной фольклорный жанр жизненно необходим. 


\section{Мировоззренческая основа традиционной культуры и адаптация к современному миру ее составляющих}

Говоря об адаптации традиционной культуры к современному миру, нельзя не затронуть проблему мировоззрения, ментальности. Мировоззрение обусловливает все формы и проявления народной культуры, и, в свою очередь, все формы и проявления традиционной культуры проецируются на определенное мировоззренческое поле. Само понятие «фольклорная традиция», как замечает Сергей Неклюдов, «включает в себя по крайней мере четыре аспекта: «субстанциальный», «структурный», «технологический» и "прагматичный». Первый определяется содержательными характеристиками (картина мира, концепты, символы, образы), второй - морфологической организацией составляющих ее текстов, третий - способом их коммуникации (хранение, передача и воспроизведение сообщений), четвертый - спецификой их функционирования» (Неклюдов 2002: 3).

Самуэль Престон Бэйард, когда говорит о ментальности, акцентирует внимание на «традиционных идеях»: «Существуют в любом обществе, составляя его всеобщее достояние, так называемые традиционные идеи: они частью вообще непреходящи, всегда актуальны, частью просто долго живущие; они мощно влияют на общество, проявляя свою эффрективность в виде разнообразных социальных проявлений, которые способны к адаптации в самых разнообразных обстоятельствах, к саморазвитию и аккумуляции вокруг себя новых результатов» (Bayard 1953: 9). Борис Путилов считает, что прежде всего здесь имеются в виду преимущественно разнообразные верования, действия, эмоции (Путилов 2003: 29). По Бэйарду, материал фольклористики составляют, в первую очередь, традиционные идеи, которые получили выражение в конкретных результатах (products). К числу фундаментальных относятся 4 группы идей:

1) Понятия о происхождении, природе и регуляции вселенной и всех ее творений.

2) Понятия о мире сверхъестественного или божественных сил и отношениях человека с ними.

3) Понятия о мудрости, естественной и сверхъестественной, ее источниках, достижениях и применениях. 
4) Понятия о героизме (или силе), красоте, ценности и правильности в социальных явлениях и общественных связях, а также о противниках и противоположных качествах и выражениях, включая юмор, гротеск, зло (Bayard 1953: 9).

Обобщая и упрощая схему Бэйарда, в структуре мировоззрения традиционной культуры можно выделить следующие основные составляющие: вера (народная религиозность); верования (в том числе народная мифология, правила, запреты, приметы и т. п.), обусловленные системой мифологического мышления; ценности (народная аксиология); мораль (нормы поведения, правила взаимоотношений).

Все перечисленные компоненты мировоззрения претерпевают в современном мире существенные изменения, и именно от них зависит адаптация собственно фольклорных жанров и видов к меняющемуся миру. Вместе с тем традиционные фольклорные жанры обладают высокой степенью консервативности и сохраняют по сегодняшний день в своей основе архаические элементы представлений об окружающем мире. От соотношения присущей всем фольклорным жанрам консервативности и фрорм адаптации к современному миру зависит их современное бытование на той или иной территории.

Наиболее важными составляющими мировоззрения являются вера (народная религиозность) и верования, именно они в значительной степени определяют остальные мировоззренческие аспекты, в частности, ценности, идеалы, мораль, нормы поведения, а также именно они отображаются во всех фольклорных жанрах и обусловливают их содержательный план.

В связи с тем, что белорусы в прошлом и настоящем в подавляющем большинстве являются христианами 2-х традиционных конфессий - православия и католицизма - традиционная религиозность актуализируется в народной культуре, соответственно, в виде народного православия и народного католицизма. Последние во многом определяют менталитет той или иной местной общины, образ ее мировосприятия, внутренней и внешней жизни. Некоторые исследователи считают, что именно народное христианство определило образы, содержание и смысл всей народной культуры в том виде, в каком она нам известна на сегодняшний день: «Народная духовная культура - гораздо более новый и несравненно более сложный, чем 


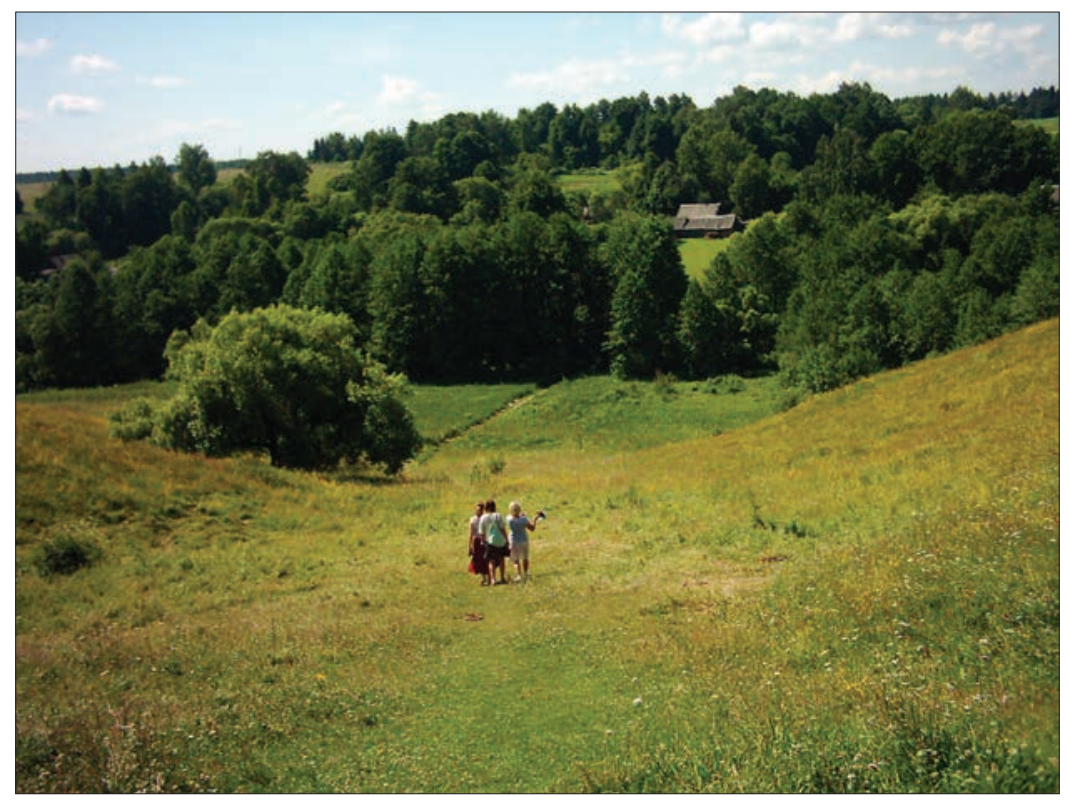

Фото 3. Дорога от кургана Радомля в деревню Александровка, Чаусский район, Могилевская область. Фото Н. Антропова.

принято думать, феномен, носящий в себе следы многовековой непрекращающейся эволюции, отправляющейся, в основном, от христианского культурного слоя. Известное единство [...] разноэтнических вариантов крестьянской европейской духовной культуры объясняется не общими глотто-этническими (индоевропейскими) ее корнями и истоками, а христианством, привнесенным в социально подобную среду. [...] Пусть это были только бледноватые копии и сильно искаженные аллюзии и вариации [христианской книжности], но своим происхождением они были обязаны таким увлекательным, поражающим воображение образам поэзии и образцам морали, с которыми не могли конкурировать ни бедное подлинное язычество, ни та возмутительная отсебятина, которую в течение двухсот лет мифологи и фольклористы выдают за реконструированное мифологическое наследие европейских народов» (Страхов 2003: 2). 
На белорусско-русском пограничье в системе народной религиозности в силу превалирования православной конфессии преобладает народное православие. С одной стороны, это чрезвычайно устойчивая система, переходящая из столетия в столетие. С другой стороны, в современном мире, тяготеющем к глобализации и унификации форм культуры, многие устные компоненты постепенно маргинализуются, выходят из активного употребления и исчезают.

Наиболее устойчивыми в системе народного православия на белорусско-русском пограничье являются те элементы, которые обладают выраженной функциональностью и являются откликом на реальные проблемы индивидуальной и коллективной жизни (здоровье, благосостояние, мир и т.п.). В силу своей функциональности на белорусско-русском пограничье сохранились (хотя в разной степени и в разной форме) обряды переноса

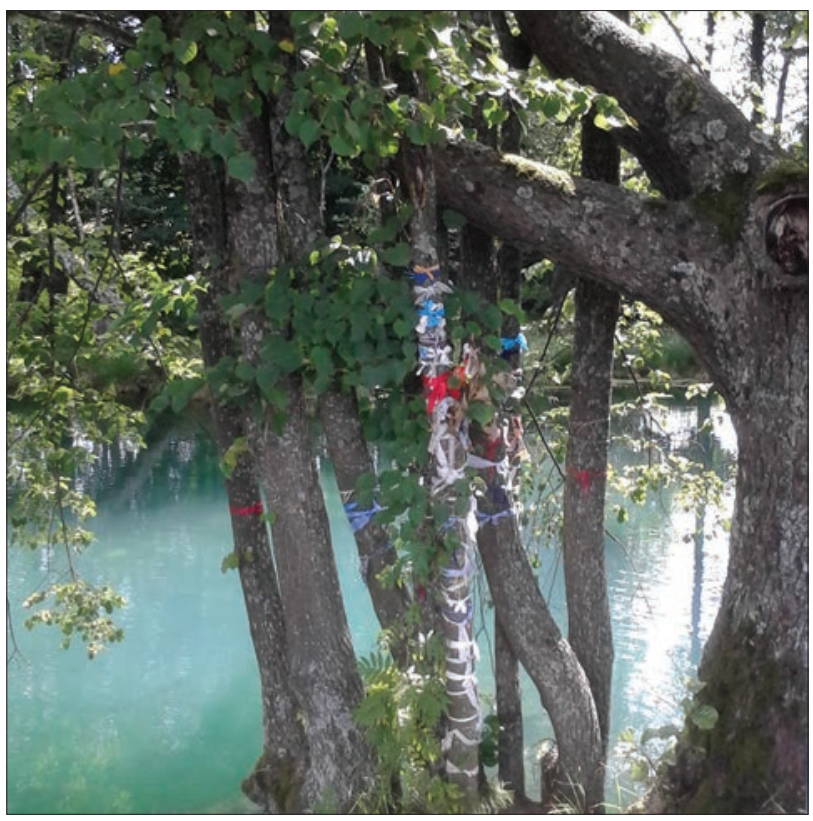

Фото 4. Источник «Голубая криница» в Славгородском районе Могилевской области. Фото Е. Боганевой. 
«свечи», связанные с оброками их участников; почитание святых источников, вокруг которых в местных традициях бытует множество преданий, поверий, историй исцелений.

На примере преданий о святых источниках можно проследить соотношение обычая и верования. Сначала зарождается верование, например, в целительную силу источника, затем складываются обычаи, обряды, например, освящения воды в определенный церковный праздник, после чего формируется определенный хронотоп праздника, обрядовые действия, атрибуты и т.п. И затем сформированный обычай начинает, в свою очередь, оказывать влияние на актуальность и сохранность верований, преданий, устных историй.

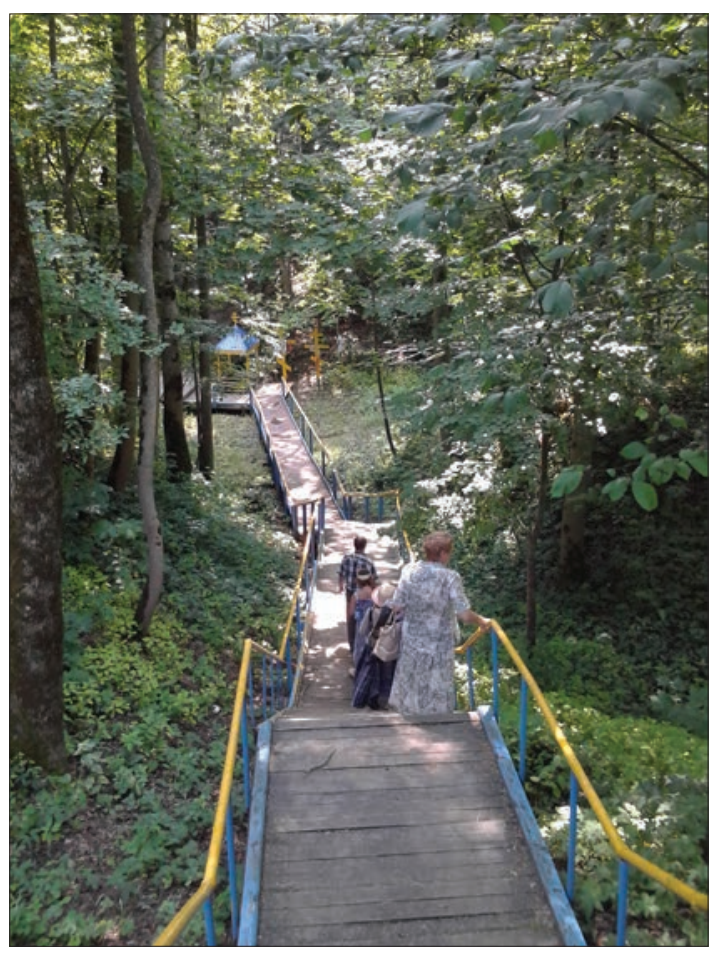

Фото 5. Дорога к источнику «Ясеневы Гай» в Краснопольском районе Могилевской области. Фото Е. Боганевой. 


\section{Современное бытование} народнобиблейской и мифологической прозы белорусско-русского пограничья ${ }^{1}$

В полное описание бытования традиционных фрольклорных жанров должны входить характеристики: а) системы жанров и их разновидностей в данной локальной культуре; б) фрорм бытования жанров (активной/пассивной) для данной территории; в) носителей традиции (гендерная, возрастная, конфессиональная, образовательная, профессиональная, статусная характеристики); г) аудитории слушателей (адресатов); д) типичных ситуаций (контекстов) коммуникации/исполнения; е) преемственности (как/от кого усвоено, кому передается); ж) некоторых особенностей актуализации и функциональности прозаических текстов; з) восприятия и оценки исполняемых произведений (Боганева 2010: 26).

Основными хранителями и трансляторами устной прозаической традиции на пограничье, как и повсеместно, являются сельские женщины - разного возраста (от 1920-х гг. рождения до 1960-х), разного уровня образования (от полного его отсутствия до высшего), различных социальных и профессиональных статусов (доярки, клубные работники, учителя, агрономы, зоотехники, бухгалтеры, пенсионеры). Но подавляющее большинство наших информантов являются пенсионерами (возраста от 55 до 90 лет), с начальным образованием, местные, традиционных конфессий (православные или католики).

Изучение локальных традиций на белорусско-русском пограничье показывает, что «нарративный фонд» этих территорий оперирует сходными комплексами сюжетов и мотивов, которые представляют собой: 1) локальные варианты общеевропейских и восточнославянских сюжетов, имеющих оригинальные мотивы в своем составе (нарративы "народной Библии», этиологические и духовно-этические легенды); 2) уникальные локальные образования, относящиеся к категории культурного диалекта (представления и былички о мифологических персонажах "доброхожих», летающих змеях, «вадунах» и др.) или микродиалекта («точечные» мифологические персонажи, такие как “дюндик», «железнячка», «полевые девки» и др.); 3) региональные и локальные варианты представлений и быличек об 
известных мифологических персонажах, таких как домовик, лесовик, полевик и др., которые существенно отличаются от сходных представлений о тех же персонажах на других территориях Беларуси и также относятся к отличительным чертам культурных диалектов пограничья.

Форма сохранности того или иного жанра (активная или пассивная) зависит, во-первых, от знакомства с текстами и сюжетами широкого круга носителей традиции; во-вторых, от наличия мастеров-рассказчиков; в-третьих, от степени востребованности жанра и его способности решать определенные задачи для современной аудитории; в-четвертых, от наличия этой аудитории - адресата (любой нарративный жанр обязательно адресно направленный и предусматривает слушателя).

Нарративы «народной Библии», этиологические легенды, предания о местных достопримечательностях продолжают сохраняться в памяти носителей традиции старшего поколения, однако в современном мире они все больше переходят в пассивную форму, когда останавливается их преемственность: их еще помнят, но почти не передают.

Что касается «народной Библии», которая является важной частью народного христианства, то она постепенно утрачивает свои позиции в современной культуре. «Народная Библия» была на протяжении столетий одним из самых представительных «зеркал», отражающих народную религиозность, ментальность, представления о ценностях. Устной Библии, фрункционирующей в той или иной локальной или региональной общности и культуре, принадлежит область не только определенных традиционных знаний об устройстве мира, происхождении разных видов существ, явлений, предметов, установлений, но также область общих смыслов и представлений об этических категориях добра и зла, блага и ущерба, греха и добродетели (см. об этом Боганева 2015a: 285-302). На современном этапе на белорусско-русском пограничье фольклорная Библия еще очень распространенный и активный корпус текстов, однако уже среди ограниченного круга информантов - либо среди представителей самых старших поколений носителей традиции, либо в среде «знающих» (шептух, знахарок).

Устная Библия в условиях повсеместного распространения и доступности Священного Писания постепенно перестает быть актуальной для поколений, воспитанных в мире преимущест- 
венно письменного типа культуры. Тем не менее на белорусско-русском пограничье в современных условиях сохраняются (в основном в среде старшего поколения) и многократно записывались народнобиблейские нарративы о сотворении первых людей; о ногтевом теле, скрывавшем признаки пола у Адама и Евы; о происхождении кадыка на горле у мужчин (Адам подавился запретным яблоком); о спрятанных детях Адама и Евы, из которых произошли невидимцы («доброхожие», «домовые» и т.п.); о Каине и Авеле на луне; о Великом потопе; Вавилонской башне; Илье-пророке как распорядителе грозы; о благовещении и рождении Христа; о животных, чье поведение возле яслей с новорожденным Христом обусловило дальнейшие их свойства и отношение к ним людей как к «святым» (коровы, овечки) и «грешным» (кони, свиньи); об иконе Троеручица (как Бог дал Божией Матери третью руку, чтобы она могла переплыть реку с младенцем-Христом и спастись от преследователей) и др. Все эти сюжеты также были зафиксированы в сборниках XIX - нач. $\mathrm{XX}$ вв. Владимиром Добровольским, Павлом Шейном, Евдокимом Романовым. Практически исчез из современного бытования апокрифический сюжет о рукописании Адама - передаче умерших сатане до времени воплощения Спасителя - Христа, однако даже он в 1990-х гг. еще фокксировался на белорусскорусском пограничье (Лопатин 2008: 187-188).

Многие народнобиблейские тексты на белорусско-русском пограничье содержат либо редкие для белорусской народной Библии мотивы, либо нетипичные детали, повороты сюжета, которые, тем не менее имеют аналоги в других регионах Беларуси или этнических традициях. Т.е. эти редкие варианты аккумулируют в себе особенности самых разных традиций. Например, к общераспространенному народнобиблейскому мотиву о «роговом» или «ногтевом» теле первых людей (фиксируемому на этой территории еще в конще XIX века Владимиром Добровольским (Добровольский 1891: 236) неожиданно добавляется заговор от сглаза и испуга, отсылающий к ситуации прецедента - легендарному ногтевому телу первых людей. Поскольку бытовая заговорная традиция является чрезвычайно актуальной для белорусско-русского пограничья, благодаря заговору представление о ногтевом теле Адама и Евы сохранилось в памяти рассказчицы. "I ешчо гаварілі так: у Адала $i$ у Eвь была кожа, такая, как вот у нас ногиі. Полнасьцю пакрыты 
былі такой. I січас у чалавека асталісь астатачкі, толькі ногиі. I січас есьиь такой прыгавор, бабушка гаваріла, вот як будта бы спасенье ат всякіх бед. Ана гаваріла, нада ўзяиь мізінчык этат вот, правесьиі над бравяли і сказаць: "Адалава кожа, сахрані мяня, Божа, ад чорных бравей да бельх ног”. Бывает знаеце как? Чалавек слотріт $i$ васпрінілает ета усё, так васпрінілает, што дажа прінілает на сябе. Так вот штоб плахое не перяйшло на иябе, нада вот так дзелаць. Часта бывает, па иелявізару слотріш - страшна такое ууё паказваеица, і перяжьваеица і дулаеица... Узял так $і$ сказал» (зап. Е. Боганева и Т. Володина в 2012 г. от Раисы Кабанцовой, 1939 г. р., д. Мышевое Костюковичский р-н. Могилевская обл.).

В последние годы на белорусско-русском пограничье неоднократно был записан редкий сюжет о спрятанных детях Адама и Евы (ATU 758) (Uter 2004), из которых произошли невидимые люди (в других вариантах - домовые, лесовые и т.п.) (см. об этом

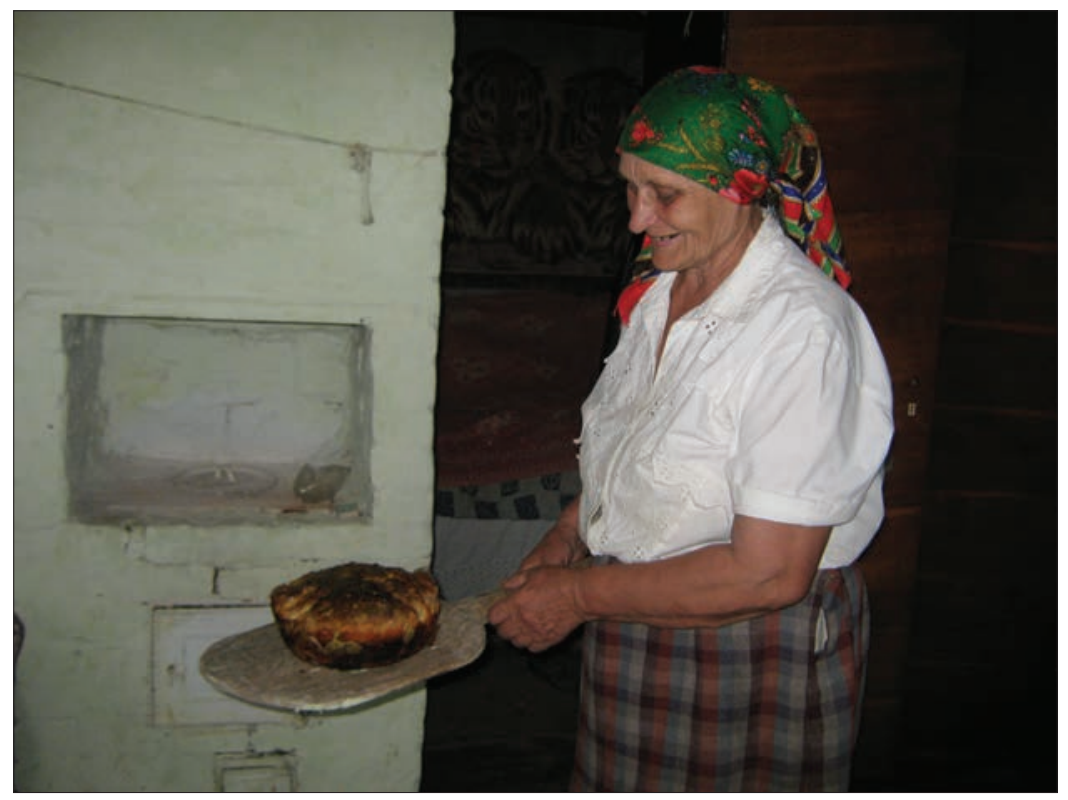

Фото 6. Раиса Кабанцова, деревня Мошевое, Костюковичский район, Могилевская область. Фото Е. Боганевой. 
сюжете Белова \& Кабакова 2014: 66-68, 344-346; 2015: 109-120). «Ну, калі ж Бог саздаў іх, і яны сталі жыць улесьці. І радзілі... Дак яны ўзялі і радзілі етых... Наражалі лнога дзяцей. Прішоў Бог к іл і давай спрашываць: а яны баящиа. І уззялі сагряшылі. Адали гаворя на Еву: “Давай!..” I вот паддуріў жа! I вот мы ўсегда паддуренья жэншчьны. Да, паддуренья усё урреля. Гаворя: "Давай не прізнаелся, што многа, давай скажал шэсиь, шэсиь схаваел”. Шэсиь схавалі, а шэсиь паказалі. Бог жа пабачьў, знаў жа ета ууё, $і$ гаворя: "Вы ж мяне абланулі! Ну, ияперь вали не бачьць етьх дзяцей шасьцёх, а етьх будзеце расьціиь”. Ну так ета дзеиі пашлі странстваваць, так. І паказуюица людзял, $i$ бачуиь людзі, $і$ у кажнал далу ё свой далавый. [Так гэта дамавыя?] Да, ета далавыя так абразавалісь. [А іх невідзімымі людзьмі называюць?] Да, невідзілылмі людзьлі» (зап. Е. Боганева в 2016 г. от Марии Васильевны Гумбар, 1949 г. р., прав., 8 кл., д. Курбаки, Краснопольский р-н, Могилевская обл.). «[Ці былі такія ў вас дабрахожыя? Нявідзімыя, багатыры?] $H y$, эта такое дзела, што... Такія людзі, што іх нада... Маліциа за іх нада. Такія людзі. Было дванациаць дзіцёнкаў у сял’і. Янь шэсьць пахрысьцілі, а шэсьць іскрылі. Вот і называециа ета невідзілиы. А янь людзі такія, як і мы. Укажнал дварэ ё. На іх маліциа нада. Прасіць нада іх. I не нада нічога плахога нідзе сказаць... На двор іціць нада на такое, штоб стала места, адно бьлло, схадзіць на двор, о» (зап. Е. Боганева и И. Смирнова в 2016 г. от Евфросинии Демчихиной, 1934 г. р., прав., образ. не имеет, д. Неглюбка, Ветковский р-н, Гомельская обл.).

Текст из Ветковского района Гомельской области демонстрирует процесс постепенной трансформации сюжетной канвы и главных действующих лиц - вместо Адама и Евы фигурирует безымянная «семья», которая уже непонятно от кого скрыла своих некрещеных детей. Данный сюжет в своем классическом виде фриксировался в конце XIX. Владимиром Добровольским (Добровольский 1891: 87-89), Евдокимом Романовым (Романов 1891: 157) и в начале $1990-x$ ХХ в. Геннадием Лопатиным (Лопатин 2008: 187-188). Впоследствии сюжет считался утраченным, поскольку не встречался в ходе экспедиций 2002 и 2004 гг. по Гомельско-Брянскому пограничью (центральному ареалу бытования доброхожих) (Боганева 2009: 14). Запись его в разных местах белорусско-русского пограничья (Ветковском районе Гомельской области и Краснопольском районе Могилевско 


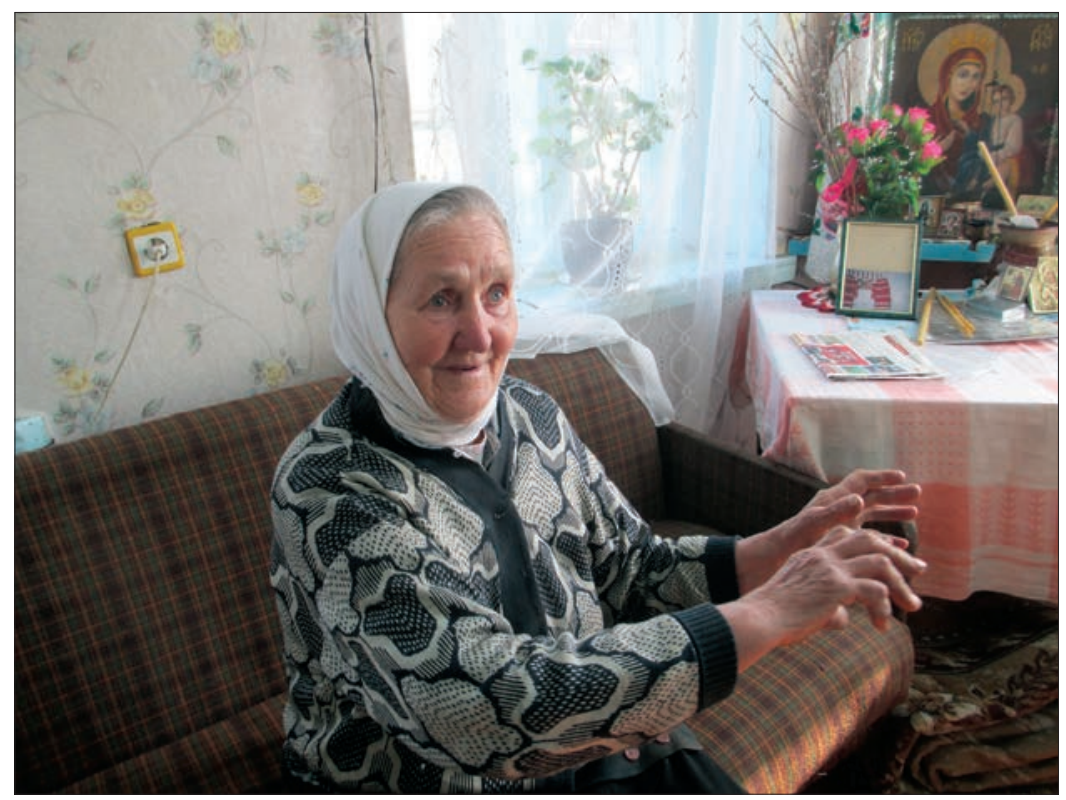

Фото 7. Евфросиния Демчихина, д. Неглюбка, Ветковский р-н, Могилевская обл. Фото Е. Боганевой.

области) в 2016 г. свидетельствует о высокой степени общей сохранности текстов народной несказочной прозы на этой территории.

Вместе с тем бытование «народной Библии» неоднородно на разных территориях белорусско-русского пограничья. Если в Добрушском, Чечерском, Ветковском районах гомельско-брянского пограничья, Костюковичском, Хотимском, Климовичском, Чериковском, Кричевском, Краснопольском, Славгородском районах Могилевско-Смоленского пограничья «народная Библия» актуальный и активный для информантов старшего поколения корпус текстов, то для Горецкого, Шкловского районов Могилевской области и Витебского района Витебской области устная народнобиблейская традиция обнаруживает крайнюю бедность в общем распространении, она не актуальна для широкого круга носителей традиции. Самые распространенные в других регионах Беларуси темы фольклорной Библии, такие 
как о сотворении и грехопадении первых людей, Великом потопе, Вавилонской башне, рождении Христа, бегстве Святого семейства в Египет, страстях, распятии и воскресении Христа не характерны здесь для устного бытования. Соответственно, народнобиблейские этиологические сюжеты о происхождении кадыка на горле у мужчин, о том, почему конь не наедается, почему корова и овечки «святые», почему осина дрожит, почему евреи не едят свинину, цыгану можно красть и др. также практически неизвестны. Самыми популярными и широко известными сюжетами являются эсхатологические предсказания перед концом света и рассказы о т. н. «старой Библии». Носители яркой народнобиблейской традиции, с полным охватом топиков, оригинальным пересказом основных сюжетов встречались в этих районах преимущественно среди «знающих» - шептух, знахарок.

Актуальным и активным жанром продолжают оставаться былички (мифологические нарративы). Они передаются не только от старшего поколения младшему, но и по «горизонтальным» возрастным связям: столкновение со сверхъестественным, необычайным с точки зрения повседневной рациональности никогда не перестает волновать человека. На сегодняшний день былички - один из самых широко распространенных в деревне жанров как среди людей самого старшего поколения, так и среди сравнительно молодых информантов (от 1950 г. р.). При этом среди носителей традиции разных поколений, разного образовательного и социального статуса имеется определенная неоднородность в восприятии образов сверхъестественного и «страшного» (см. об этом Боганева 2010: 27).

Восточное русско-белорусское пограничье характеризуется по сравнению с остальной территорией Беларуси наличием разнообразного состава мифологических персонажей (домовики, хлевники, полевики, лесовики, русалки, невидимые люди, летающие змеи и др.), тогда как на белорусско-польском пограничье этот состав ограничивается домовиками и русалками.

В результате полевых исследований в 2016 г. по Ветковскому району Гомельской области, Краснопольскому и Славгородскому районам Могилевской области, уточнен ареал распространения поверий о таких характерных только для белорусско-русского пограничья мифрологических персонажах, как невидимцы (доброхожие, богатыри, невидимые люди). Условно «центр» ареала 
можно охарактеризовать наличием конкретного мифонима, даже если персонаж смешивается или отождествляется с другими духами локусов (домовиками, лесовиками, полевиками, русалками). На периферии ареала мифоним отсутствует, но имеются более или менее выразительные следы верований об этом персонаже - мотивы и характеристики образа. По имеющимся на сегодняшний день текстам о невидимых людях в ареале отчетливо выделяется основная центральная зона: восточные, приграничные с Россией части Ветковского, Чечерского районов Гомельской области, и, соответственно, западные, приграничные с Ветковским и Чечерским районами части Новозыбковского и Красногорского районов Брянской области. На юге этот ареал ограничивается Ветковским и Новозыбковским районами, на севере - южной частью Краснопольского района Могилевской области, которая граничит с Красногорским районом Брянской области (см. о невидимых людях (Боганева 2017: 16-20).

Распространены сейчас также в активной форме легендыбылички (рассказы о чудесах), легендарные рассказы о чудотворных иконах, помощи святых, Божией Матери, вещих снах и т. п. Бытование этих нарративов в меньшей степени зависит от возраста, пола, образования, принадлежности к устной или письменной традиции, главное значение здесь имеет мировоззрение, вера в Божий Промысел, конфессиональная принадлежность (см. об этом Боганева 2009а: 243-251).

Система локальных верований, а также связанных с ними мифологических персонажей, является нестабильной, активно меняющейся в современном мире. В среде поколений старшего возраста, носителей преимущественно устной традиции, сохраняются традиционные сюжеты и представления о мифологических персонажах. В среде сельской интеллигенции среднего возраста в связи с распространением знаний о традиционных персонажах народной мифологии через письменные источники мифологические нарративы адаптируются к современной действительности путем аккумулирования в своем содержательном плане местных и привнесенных элементов верований и образования некоего эклектичного целого.

Показательными в этом отношении являются локальные верования относительно такого популярного персонажа белорусско-русского пограничья, как домовик. Часто представления об этом персонаже - только объяснительная матрица для не- 
объяснимых с точки зрения обычной рациональности событий, при том что знания привлекаются из самых разных традиций и источников. Как именно это происходит, дает представление следующий текст из д. Сущево Витебского района Витебской области, записанный от заведующей местным клубом 1956 года рождения, имеющей среднее специальное образование. «[Вы думаеце, дамавік ёсць?] Ёсьць, я убедзілася. Эта было так. Мала мая палиёрла осенню. А вясной [яшчэ да яе смерці] я лягла спаць. Як гавораць, лне мальлм-лало спалось, но ва сьне прівідзелось. Вот такое састаянье, када ты яшчэ не заснуў, але $і$ не ня сьпіш. Такое ў дремаце. I вот я чуствую, што мяне хто-та давіць. От ложыць на грудзі сюда і давіць, панімаеце? I вот мне трызьнециа, што нада падняиь руку і перакрысьціица. Я паднілаю эту руку - а рука такая, как будта уе ёй калні. Я перахрысьиілася, і ета усё прапала. Ну было так $i$ было, я пра ета $i$ забылася. А патол мала палёрла осенню, $i$ я стала с адной разгаварываць - а у яе мужык палёр - $i$ яна гаворыць: "От пайшоў мужык на работу... А как я узнала, што ён памрэиь? Пайшоу мужык на работу, я яго выправадзіла i лягла сала, і стала дралащь. I чую што-та па хаще: тапуmany-many. I стаў мяне душыць. Я, - гаворыць, - пра гэта ујжэ знала і спрашую: к худу иі к дабру? I так што-та даўлянула міне і ушло". 3 Мурланска прыехала тая жанчьна, а сала яна з Магілёушчыны. Тал яны как-та большэ зналі пра ета усё, тали как-та большэ сахранялася наверна, чыл у нас тут. Iя тадь, када прааналізіравала ета - што да, ета мяне давілі, предупреждалі, што мама памрещы» (зап. Е. Боганева в 2013 г. от Ларисы Шидловской, 1956 г. н., прав., среднеспециальное образ., род. в д. Гребенёва Оршанскога р-на, живет в д. Сущево, Витебский район, Витебская область).

Подобных текстов, записанных от местной интеллигенции на белорусско-русском пограничье достаточно много, и они представляют собой именно продукт адаптации традиционных верований к современному миру, а также к объяснению некоторых труднообъяснимых френоменов.

$$
* * *
$$

На примерах бытования жанров народной прозы на белорусскорусском пограничье очевидны некоторые общие закономерности 
адаптации традиционных жанров к изменяющимся условиям современного мира.

На современном этапе существуют 2 фороы адаптации народной прозы.

1) функционирование видов и жанров в естественной, аутентичной среде, когда виды и жанры приспосабливаются к новым коммуникативным ситуациям и задачам, потребностям и особенностям восприятия аудитории.

2) организованное выявление, изучение, фиксация традиционных жанров в сорерах культуры и образования, организация преемственности и трансляции (во вторичных фрормах).

Традиционные жанры народной прозы адаптируются к условиям современного мира в результате смешения и взаимовлияния письменной и устной традиций. Несмотря на практически всеобщую грамотность носителей традиции и наличие у них как минимум начального образования, информанты на белорусско-русском пограничье воспроизводят традиционные жанры (преимущественно несказочной прозы: нарративы народной Библии, этиологические и духовно-этические легенды, предания, былички, рассказы о чудесах или легенды-былички) в соответствии с традиционными мировоззренческими моделями: религией, ценностями и идеалами, моралью и нормами поведения, мифологическими представлениями о сверхъестественных силах - духах локусов (домовике, русалках, лесовике, полевике и др.). Каждый жанр и вид народной прозы, который находится в активном бытовании, с одной стороны, сохраняет свою традиционную составляющую (оставаясь в так называемой«центральной зоне культуры», от которой зависит идентичность этноса и которая является источником символов, задавая способ их упорядочения), с другой стороны, встраивается в современную культуру, модернизируясь и получая порой стимул «второй жизни» благодаря вторичным организованным формам сохранения традиции (как, например, в случае обрядов со «свечой», которые задают воспроизводство и трансляцию разнообразных меморатов и фрабулатов - об оброках, местных сакральных местах, помощи и наказании от Бога и т.п.). 


\section{Примечание}

1 Этнокультурные исследования белорусско-русского пограничья целенаправленно осуществляются с 2011 г. благодаря серии совместных белорусско-русских проектов. См. о них: http://www.ruthenia. ru/folklore/folklorelaboratory/pogranichje/about.htm. Публикации по темам проектов: http://www.ruthenia.ru/folklore/folklorelaboratory/ pogranichje/publications.htm.

\section{Литература}

Авілін, Цімафей \& Антропаў, Мікалай \& Боганева, Алена 2016. Русалкі: знешні выгляд. Беларускі фбальклор. Матэрылльь i даследаванні 3, сс. 32-273.

Авілін, Цімафей \& Аліферчык, Таццяна \& Боганева, Алена 2018 (в печати). Беларускія міфралагічныя наратывы і павер'і пра ваўкалакаў. Беларускі фбальклор. Матэрылль і даследаванні 5.

Антропов, Николай \& Авилин, Тимофей \& Боганева, Елена 2018 (в печати). Белорусско-инославянские изодоксы в картографрической проекции. Дакладь беларускай дэлегацыі на XVI з'зд славістаў (Белград, 20-27 жніўня 2018 г.) Мовазнаўства. Літаратуразнаўства. Фальклор. Мінск: Беларуская навука.

Белова, Ольга \& Кабакова, Галина (сост. и коммент.) 2014. У истоков лира: Русские этиологические сказки и легендь. Москва: ФОРУМ; НЕОЛИТ.

Белова, Ольга \& Кабакова, Галина 2015. Разные дети Евы: локальные «демонологические» версии сюжета ATU 758. Дмитрий Антонов \& Ольга Христофорова (отв. ред. и сост.). In Umbra: Делонология как семиотическая систела 4. Москва: Индрик, сс. 109-120.

Боганева, Елена 2007. Региональность сюжетно-тематического фронда народных легенд белорусского «Запада» и «Востока»: (по материалам фольклорно-этнографических исследований белорусского Западного, Центрального, Восточного Полесья и Нижнего Поднепровья 1999-2005 гг.). Александр Каргин (отв. ред.). Первый Всероссийский конгресс фбольклористов: сборник докладов. Т. 4. Москва, сс. 196-204. 
Боганева, Елена 2009. «Харошыя были людзи, толька их не видзеу нихто...» (мифологические тексты о доброхожих по материалам экспедиций 2002-2004 гг.). Живая старина 4, сс. 14-16.

Боганева, Алена 2009а. Жанравая спецыфіка і функцыянальныя асаблівасці вусных апавяданняў пра цуды ў традыцыйнай сельскай культуры. Пад навуковай рэдакцыяй Рымы Кавалёвай, Вольгі Прыемка. Фалькларыстычныл даследаваннні: кантэкст, тыпалогія, сувязі 6. Мінск: Бестпрынт, сс. 243-251.

Боганева, Елена 2010. Бытование жанров народной прозы в современной белорусской деревне (активная и пассивная формы). Живая старина 4, сс. 26-29.

Боганева, Алена 2015. Беларускія версіі легенды пра колас: варыянтнасць, тыпавыя і рэдкія матывы, геаграфія распаўсюджання. Беларускі фбальклор. Матэрыялы і даследаванні 2. сс. 171-189.

Боганева, Елена 2015а. Ценностные представления белорусов о вере: белорусская «народная Библия» и комментарии носителей традиции. Светлана Толстая (отв. ред.). Категории оценки и система иенностей в языке и культуре. Москва: Индрик, сс. 285-302.

Боганева, Алена \& Авілін, Цімафей 2017. Плямы на месяцы. Беларускія інтэрпрэтацыі. Беларускі фбальклор 4, сс. 112-149.

Боганева, Елена 2017. «Невидимцы»: сюжетные версии (белорусские деревни Неглюбка и Курбаки). Живая Старина 4, сс. 16-20.

Добровольский, Владимир 1891. Смоленский этнографический сборник. Часть 1. Записки императорского русского географического общества по отделению этнографбии. Т. ХХ. С.-Петербург.

Лопатин, Геннадий 2008. О народной демонологии белорусскобрянского пограничья: доброхожие, невидимые и др. Palaeoslavica XVII (2). Cambridge, cc. 183-217.

Маркарян, Эдуард 1978. Об исходных методологических предпосылках исследования этнических культур. Методологические проблемы исследования этнических культур: Материаль симпозиума. АН СССР. Ин-т этнографии им. Н. Н. Миклухо-Маклая, АН АрмССР. Ин-т философии и права. Ереван, изд-во АН АрмССР, cc. $6-16$. 
Маркарян, Эдуард 1983. Теория культуры и современная наука. Логико-методологический анализ. Москва: Наука.

Мид, Маргарет 1988. Культура и мир детства. Избранные произведения. Пер. с англ. и коммент. Ю. Асеева, составление и послесловие И. Кона. Москва: Наука.

Неклюдов, Сергей 2002. Фольклор: типологический и коммуникативный аспект. Традиционная культура 3, сс. 3-7.

Страхов, Александр 2003. Ночь перед Рождеством: народное христианство и рождественская обрядность на Западе и у славян. Palaeoslavica XI. Cambridge.

ТБКМ 2004 = Традыцыйная мастаикая культура беларусаў. У 6 т. T. 2. Віцебскае Падзвінне. А. М. Боганева (і інш.); агул. рэд. Т. Б. Варфаламеевай. Мінск: Вышәйшая школа.

Чистов, Кирилл 1981. Традиция, «традиционное общество» и проблема варьирования. Советская этнографбия 2, с. 106.

Чистов, Кирилл 1986. Народнье традиции и фбольклор. Очерки теории. Ленинград: Наука.

Чистов, Кирилл 2005. Фольклор. Текст. Традищия: [сборник статей]. (Рос. гос. гуманитар. ун-т, Ин-т высш. гуманитар. исследований, Центр типологии и семиотики фольклора; подгот. текста к изд. А. С. Архиповой). Москва: ОГИ.

Эйзенштадт, Шмуэль 1998. Новая парадигма модернизации. Б. С. Ерасов (сост., ред. и вступ. ст.). Сравнительное изучение иивилизаций: Хрестолатия: Учеб. пособие для студентов вузов. Москва: Аспект Пресс, сс. 470-479.

Bayard, Samuel P. 1953. The materials of folklore. Journal of American Folklore 259, cc. 7-17.

Eisenstadt, Samuel 1973. Tradition, Change, and Modernity. New York, Sydney, Toronto: John Wiley.

Shils, Edward 1961. Centre and Periphery. The Logic of Personal Knowledge: Essays. London, Ronthedge and Kegen Paul, cc. 281-301.

Uther, Hans-Jörg 2004. The Types of International Folktales. A Classification and Bibliography. Part 1-3. FFC 284. Helsinki. 


\section{Summary}

\section{Traditional Folklore Genres Adaptation to Contemporary Context (Examplified by Folk-Biblical and Mythological Narratives of Belarusian-Russian Borderland)}

\section{Elena Boganeva}

Keywords: adaptation, "central zone of culture", ethnic culture, folk Bible, folk prose, folk religiosity, mythological narratives, oral and written types of culture

The term "adaptation" in anthropology and culturology stands for the process of mutual adjustment between culture and its environment, which is aimed at the survival and stability of the social system. Culture cannot exist beyond tradition; oral ethnic culture has the strongest bonds with tradition as it is the "central zone of culture" (Shils, Eisenstadt) and remains stable regardless of the change of invariants in the cultural tradition. As long as this "central zone" stays intact, an ethnos keeps its identity. Therefore, ethnic culture is the basic "central" structure that consolidates a society and prevents it from disintegration. In the rural areas of Belarus living ethnic culture still exists, even though it has undergone various transformations in order to adapt to modernity and at the same time to adapt its bearers to new reality. There is a mixed type of culture in Belarusian villages: there is both written and traditional oral culture, and it is the oral tradition that defines the worldview, life perception and the religiosity of older generations of rural dwellers. Folk Orthodoxy is dominating the folk religious landscape of Belarusian-Russian borderland. On the one hand, it is a very stable system, on the other hand, plenty of oral elements including some variations of folk prose that are intricately connected to folk religiosity are being gradually marginalized and are not used anymore in the contemporary world with its tendencies of globalization and homogenization of cultural forms. Nevertheless, folk biblical narratives about key biblical topics and traditional plots and ideas about mythological characters are kept and often recorded at the Belarusian-Russian borderland, mainly among the older generation. Due to the spread of knowledge about traditional folk mythological characters via written sources amongst rural middle-aged intellectuals they adapt 


\section{ЕЛЕНА БОГАНЕВА}

the genre of bylichka (mythological narrative) to contemporary reality by accumulating local and introduced belief elements in its plot and creating an eclectic whole. 


\section{МИССИЯ ВЫПОЛНИМА Перспективы изучения фольклора}

http://www.folklore.ee/rl/pubte/ee/sator/sator19/

ISSN 1736-0323

ISBN 978-9949-586-60-8

DOI: $10.7592 /$ Sator.2018.19

Тарту 2018

Редакторы-составители выпуска:

Маре Кыйва \& Татьяна Володина

Редактор серии: Маре Кыйва

Фото: Яак Кикас, 2018 «Осень в Тарту»

Оформление обложки: Лииса Весик

Верстка \& HTML: Диана Кахре

Печатное издание: МИССИЯ ВЫПОЛНИМА:

Перспективы изучения фольклора. SATOR 19. Тарту 2018

Публикация книги осуществлена совместно Эстонским литературным музеем и Центром исследований белорусской культуры, языка и лит ерат уры Националь ной акад емии наук Б еларус и, п ри поддержке Министерства образования и науки Эстонии (IUT 22-5), Фонда регионального развития ЕС (ТK 145, Центр компетенции по Эстонским исследованиям); при поддержке проекта, финансируемого Министерством иностранных дел Эстонии из бюджета по сотрудничеству и развитию, Эстонской Академией Наук и Национальной академии наук Беларуси.

Оформление электронного издания осуществлено при поддержке проекта ЕККМ14-344 “Расширение областей применения и представление эстонского языка, культуры и фольклора в электронных информационных средствах".

() Эстонский литературный музей

(c) Авторы

(с) Яак Кикас 